\title{
Effect of interactions between $A P O E$ and ESR1 polymorphisms on cognitive functions in postmenopausal women
}

Jarosław Pinkas ${ }^{1}$, Iwona Bojar ${ }^{2}$, Mariusz Gujski ${ }^{3}$, Beata Sarecka-Hujar ${ }^{4}$, Alfred Owoc ${ }^{5}$, Dorota Raczkiewicz ${ }^{6}$

\author{
${ }^{1}$ School of Public Health, Center of Postgraduate Medical Education, Warsaw, Poland \\ ${ }^{2}$ Department of Women's Health, Institute of Rural Health, Lublin, Poland \\ ${ }^{3}$ Department of Prevention of Environmental Hazards and Allergology, \\ Medical University of Warsaw, Poland \\ ${ }^{4}$ Department of Pharmaceutical Technology, Medical University of Silesia, Katowice, \\ Poland \\ ${ }^{5}$ Polish Society of Social Medicine and Public Health, Poland \\ ${ }^{6}$ Department of Demography, Institute of Statistics and Demography, Collegium \\ of Economic Analysis, SGH Warsaw School of Economics, Warsaw, Poland
}

Submitted: 9 September 2017

Accepted: 13 November 2017

Arch Med Sci 2021; 17 (1): 31-39

DOI: https://doi.org/10.5114/aoms.2018.72972

Copyright (c) 2018 Termedia \& Banach

\section{Abstract}

Introduction: During menopause the level of estrogens is decreased, which may lead to cognitive impairment or dementia. Some forms of genetic polymorphism were found to be related to cognitive functions, including $A P O E$ and ESR 1 ( $P$ vull and Xbal) polymorphisms. In the present study we aimed to analyze the impact of interactions between $A P O E$ and ESR 1 polymorphisms on cognitive functions in the group of postmenopausal women.

Material and methods: The study group consisted of 266 postmenopausal women aged 50-65 years without symptoms of dementia. A computerized battery of the Central Nervous System Vital Signs (CNS VS) test was used to diagnose cognitive functions. APOE and ESR 1 polymorphisms were genotyped using multiplex PCR and PCR-RFLP methods, respectively. Statistical analysis was performed using two-way analysis of variance in Statistica software.

Results: The best memory, visual memory, processing and psychomotor speeds were found in women carrying the $C$ allele of the Pvull polymorphism ( $T C+C C$ genotypes) in the presence of the APOE $\varepsilon 2 / \varepsilon 3$ genotype, while a lower outcome was noted in women with $\varepsilon 3 / \varepsilon 3$, and the lowest if they had the $\varepsilon 4$ allele. In the case of women with TT genotype of the Pvull polymorphism, cognitive functioning did not decrease in women with the $\varepsilon 4$ allele. A similar effect on cognitive functions was observed for $A G+G G$ genotypes of the $X b a l$ and $A P O E$ polymorphisms. Women who simultaneously carried CC Pvull and GG Xbal genotypes had the lowest cognitive functions.

Conclusions: Interactions of polymorphic variants of APOE and ESR 1 genes influenced cognitive functions in postmenopausal women.

Key words: apolipoprotein E, estrogen receptor alpha, cognition, postmenopause.

\section{Introduction}

Estrogens exert a pleiotropic effect on a woman's whole body: the skin, adipose tissue, bones, the central nervous system, cardiovascular and di-

\author{
Corresponding author: \\ Dorota Raczkiewicz \\ Department of Demography \\ Institute of Statistics \\ and Demography \\ Collegium of Economic \\ Analysis \\ SGH Warsaw School \\ of Economics \\ 162 Niepodleglosci St \\ 02-554 Warsaw, Poland \\ Phone: +48 605313261 \\ E-mail: dbartos@sgh.waw.pl
}


gestive systems, not only on the reproductive system $[1,2]$. Previous reports identified the role of estrogens in the regulation of synaptogenesis in the region of the dorsal hippocampus in female rats [3]. The naturally occurring low levels of estrogens noted before and after menopause may be related to cognitive impairments or dementia [4]. Hence, hormone replacement therapy (HRT) can reduce the risk of dementia in postmenopausal women, as confirmed by the meta-analysis of LeBlanc et al. [5].

Estrogen interacts with two estrogen receptors: estrogen receptor- $\alpha(E R \alpha)$ and estrogen receptor- $\beta$ (ER $\beta)$, encoded by ESR1 and ESR2 genes, respectively. Two polymorphisms within ESR1 (rs9340799 - 351A>G (Xbal) and rs2234693 - 397T>C (Pvull), separated by only 46 base pairs) are noted to play a role in several diseases [6-8]. It is also suggested that both ESR1 polymorphisms may have an impact on cognitive functioning $[9,10]$. However, there are also contrary results in the topic [11].

Available data establish a clear relationship between estrogens and apolipoprotein E (APOE). Earlier results also showed that the APOE $\varepsilon 4$ allele was related to a range of disorders, including lipid profile [12], Alzheimer disease (AD) [13, 14], and coronary artery disease, often in the presence of other candidate polymorphisms [15]. It was also observed that healthy individuals carrying the $A P O E \& 4$ allele had significantly worse overall verbal episodic memory than healthy non-carriers [16]. A study on mouse cortical neurons showed that estradiol influenced neurite growth through an ApoE-dependent mechanism; therefore, HRT may have a different impact on chronic neurological diseases due to the presence of a particular APOE genotype [17].

The aim of the present study was to analyze the impact of interactions between $A P O E$ and ESR 1 polymorphisms on cognitive functioning in postmenopausal women.

\section{Material and methods}

\section{Study group}

The study was conducted in 2014 at the Institute of Rural Health in Lublin, Poland. The study group comprised 266 women from south-eastern Poland. The inclusion criteria were: age 50-65 years, with a minimum period of 2 years since the last menstrual period. The exclusion criteria were: any chronic diseases within the last 5 years, medical history of mental diseases, addiction to drugs and/or alcohol, diagnosed disease entity with the symptoms of dementia, current or past use of HRT, severe menopausal symptoms according to the Kupperman menopausal index [18]. A brief Montreal Cognitive Assessment (MoCA) test was performed in order to exclude women who pre- sented with features of dementia. Only women who obtained scores of at least 26 were included in the study.

\section{Computerized neurocognitive assessment software for CNS-Vital Signs}

Assessment of cognitive functions [19] was performed based on the diagnostic equipment, CNS Vital Signs (1829 East Franklin Street, Bldg 500, Chapel Hill NC 27514, 919-933-0932). The instrument, consisting of a battery of computer tests, is standardized, and was subjected to a full validation procedure. It has many cultural and language adaptations, including one for Polish. Nine cognitive functions - Memory, Verbal Memory, Visual Memory, Processing Speed, Executive Functioning, Psychomotor Speed, Reaction Time, Complex Attention, Cognitive Flexibility - were assessed. The CNS VS test provides the Neurocognitive Index based on five cognitive functions: memory, psychomotor speed, reaction time, attention, and cognitive flexibility. Standard scores of the $\mathrm{NCl}$ and of nine cognitive functions were analyzed and interpreted as: above average (> 109), average (90-109), low average (80-89), low (70-79), very low $(<70)$, with higher values of standard scores indicating better cognitive functions.

\section{DNA isolation}

Genomic DNA isolation was derived from $0.2 \mathrm{ml}$ of human blood by the QIAamp DNA Blood Mini Kit (Qiagen, USA), as per the producer's instructions. The amount and purity of the extracted DNA were measured using the NanoDrop spectrophotometer.

\section{APOE polymorphism}

Multiplex polymerase chain reaction (PCR) was carried out according to Yang et al. [20], with some modifications. PCR reactions were made in a single reaction tube with six primers, including two common primers and two specific primers for each of two single nucleotide polymorphism (SNP) sites. The multiplex PCR reaction was carried out in a $50 \mu \mathrm{l}$ reaction volume containing the following mix of reagents: $1.25 \mathrm{U}$ Taq DNA polymerase, $1 \times$ PCR buffer containing $15 \mathrm{mM} \mathrm{MgCl}_{2}$ and $1 \times$ Q buffer (all from Qiagen, USA), $0.2 \mathrm{mM}$ each of dNTP (Fermentas, Lithuania), $0.5 \mu \mathrm{M}$ of each of six primers: FO, RO, FI-1, RI-1, Fl-2, RI-2 (Eurogentec, Seraing, Belgium), nuclease-free water (Applied Biosystems, USA) and $5 \mu \mathrm{l}$ of DNA. The reaction was performed in a C1000 Thermal Cycler (BioRad) under the following conditions: initial denaturation at $95^{\circ} \mathrm{C}$ for $5 \mathrm{~min}$, then 35 cycles (denaturation $95^{\circ} \mathrm{C}$ for $30 \mathrm{~s}$, annealing at $60^{\circ} \mathrm{C}$ for $30 \mathrm{~s}$, elongation at $72^{\circ} \mathrm{C}$ for $60 \mathrm{~s}$ ); the final extension 
step is at $72^{\circ} \mathrm{C}$ for $7 \mathrm{~min}$. The reaction products were detected in $2.5 \%$ agarose gels in the standard electrophoresis conditions. After ethidium bromide staining, the strips were read under UV light. The size of the amplified DNA fragment, using two common outer primers (FO and RO), was $514 \mathrm{bp}$. Obtained DNA amplicons flanked by each of two sets of allele-specific inner primers (FI-1/ $\mathrm{RI}-1$ and $\mathrm{FI}-2 / \mathrm{RI}-2$ ) showed different types of polymorphisms: 444 bp, 307 bp and 115 bp for $\varepsilon 3 / \varepsilon 4$; $307 \mathrm{bp}$ and $115 \mathrm{bp}$ for $\varepsilon 3 / \varepsilon 3$; $444 \mathrm{bp}$ and $307 \mathrm{bp}$ for $\varepsilon 4 / \varepsilon 4 ; 307 \mathrm{bp}, 253 \mathrm{bp}$ and 115 bp for $\varepsilon 2 / \varepsilon 3$; 444 bp, 307 bp, 253 bp and 115 bp for $\varepsilon 2 / \varepsilon 4$.

\section{ESR1 polymorphisms}

Polymorphisms of ESR 1 were determined using the restriction fragment length polymorphism (RFLP-PCR) method. PCR reaction was performed in a total amount of $50 \mu$ containing: $1 U(1 \mu \mathrm{l})$ of DNA polymerase (Biotools), 1 PCR buffer $(5 \mu \mathrm{l})$ containing $15 \mathrm{mM} \mathrm{MgCl}$ (Biotools), $2.5 \mu \mathrm{l} 2 \mathrm{mM}$ dNTPs (final concentration $0.1 \mathrm{mM}$ ) (Fermentas, Vilnius, Lithuania), $1 \mu \mathrm{l}$ of $10 \mu \mathrm{M}$ of each of the two primers, $34.5 \mu$ l nuclease-free water (Applied Biosystems Inc., USA) and $5 \mu$ l of genomic DNA. The reactions were performed in a C1000 Thermal Cycler (Bio-Rad) and consisted of the initial denaturation $\left(3 \mathrm{~min}\right.$ at $95^{\circ} \mathrm{C}$ ) and 30 cycles, each of which included the proper denaturation $(30 \mathrm{~s}$ at $95^{\circ} \mathrm{C}$ ), primer annealing $\left(50 \mathrm{~S}\right.$ at $\left.62^{\circ} \mathrm{C}\right)$, elongation $\left(50 \mathrm{~S}\right.$ at $72^{\circ} \mathrm{C}$ ), and the final elongation ( $7 \mathrm{~min}$ at $72^{\circ} \mathrm{C}$ ). Electrophoresis was performed in $2 \%$ agarose gel in standard conditions. The products of PCR (1372 bp) were digested overnight at $37^{\circ} \mathrm{C}$ using 2 separate restriction enzymes for determining the polymorphisms: Pvull (c.454-397 T>C) and Xbal (c.454-351 A>G). The products of restriction were electrophoresed in $2.5 \%$ agarose gel.

The alleles of the $\mathrm{Xbal}$ polymorphism were defined as $A$ and $G$ : heterozygote AG (fragments: 1372 bp, 936 bp, and 436 bp), homozygote GG (fragment: $1372 \mathrm{bp}$ ), and homozygote AA (fragments: 936 bp and 436 bp). The alleles of the Pvull polymorphism were defined as T and C: heterozygote TC (fragments: 1372 bp, 982 bp, and 390 bp), homozygote TT (982 bp and 930 bp), and homozygote CC (1372 bp).

\section{Statistical analysis}

The data were statistically analyzed using Statistica software. We estimated mean values (M) with standard deviations (SD) for continuous variables, and absolute $(n)$ and relative numbers (\%) of occurrence of items for categorical variables. Two-way analysis of variance was used to compare cognitive functions versus APOE and ESR1 polymorphisms. F statistics were used to test three different hypotheses: APOE polymorphism affects cognitive functions; ESR1 polymorphism affects cognitive functions; and the interaction between APOE and ESR1 polymorphisms affects cognitive functions. Due to the small sample sizes of women with $\varepsilon 4 / \varepsilon 4$ and women with $\varepsilon 3 / \varepsilon 4$, they were combined together for statistical analysis. One-way analysis of variance was used to compare cognitive functions versus interaction between $\mathrm{Xbal}$ and PvUll of ESR 1 polymorphisms due to the very small sample sizes or even empty cells in cross-sections.

The value of $p \leq 0.05$ was considered to indicate a significant difference.

Informed consent for participation in the study was obtained from all women. The study was approved by the Ethics Committee of the Institute of Rural Medicine in Lublin, Poland.

\section{Results}

\section{Study group characteristics}

A total of 266 postmenopausal women, aged 5065 years, with an average age of $56.6 \pm 3.4$ years, of mostly secondary education, were examined in the study. The majority of them were carriers of $\varepsilon 3 /$ \&3 APOE polymorphism, with approximately half of them possessing AG genotype of the ESR1 Xbal polymorphism and a little fewer having TC genotype of the ESR1 Pvull polymorphism (Table I).

\section{Cognitive functions vs. APOE polymorphism}

$\mathrm{NCl}$ and five of nine cognitive functions - executive functioning, psychomotor speed, reaction time, complex attention and cognitive flexibility depended on APOE gene polymorphism (Table II). $\mathrm{NCl}$ was assessed as average in women with $\varepsilon 3 / \varepsilon 3$ genotype, as low average in women with $\varepsilon 3 / \varepsilon 3$, as low in women with $\varepsilon 3 / \varepsilon 4$, and very low in women with $\varepsilon 4 / \varepsilon 4$. Executive functioning and cognitive flexibility were assessed as average in women with $\varepsilon 3 / \varepsilon 3$ genotype, as low in women with $\varepsilon 3 / \varepsilon 3$ and $\varepsilon 3 / \varepsilon 4$, and very low in women with $\varepsilon 4 /$ $\varepsilon 4$. Psychomotor speed was assessed as average in women with $\varepsilon 3 / \varepsilon 3$ genotype, as low in women with $\varepsilon 3 / \varepsilon 3$, and very low in women with $\varepsilon 3 / \varepsilon 4$ and $\varepsilon 4 / \varepsilon 4$. Reaction time was assessed as average in women with $\varepsilon 3 / \varepsilon 3$ genotype, and as low average in women with $\varepsilon 3 / \varepsilon 3, \varepsilon 3 / \varepsilon 4$ and $\varepsilon 4 / \varepsilon 4$. Complex attention was assessed as average in women with $\varepsilon 3 / \varepsilon 3$ genotype, as low in women with $\varepsilon 3 / \varepsilon 3$, and very low in women with $\varepsilon 3 / \varepsilon 4$ and $\varepsilon 4 / \varepsilon 4$.

\section{Cognitive functions vs. ESR 1 polymorphisms}

Three cognitive functions - processing speed, executive functioning and cognitive flexibility depended on ESR1 Pvull polymorphism (Table III). 
Table I. Study group characteristics

\begin{tabular}{|c|c|c|c|}
\hline Variable & Category & Parameter & Estimate \\
\hline Age & Years & Min.-max., mean $\pm S D$ & $50-65,56.4 \pm 3.4$ \\
\hline \multirow[t]{4}{*}{ Level of education } & Primary & $n(\%)$ & $10(3.76)$ \\
\hline & Basic vocational & $n(\%)$ & $23(8.65)$ \\
\hline & Secondary & $n(\%)$ & $128(48.12)$ \\
\hline & Tertiary & $n(\%)$ & $105(39.47)$ \\
\hline \multirow[t]{4}{*}{$A P O E$ polymorphism } & $\varepsilon 2 / \varepsilon 3$ & $n(\%)$ & $53(19.92)$ \\
\hline & $\varepsilon 3 / \varepsilon 3$ & $n(\%)$ & $157(59.02)$ \\
\hline & $\varepsilon 3 / \varepsilon 4$ & $n(\%)$ & 39 (14.66) \\
\hline & $\varepsilon 4 / \varepsilon 4$ & $n(\%)$ & $17(6.39)$ \\
\hline \multirow[t]{3}{*}{ ESR1 Pvull polymorphism } & TT & $n(\%)$ & $75(28.20)$ \\
\hline & TC & $n(\%)$ & $119(44.74)$ \\
\hline & CC & $n(\%)$ & $72(27.07)$ \\
\hline \multirow[t]{3}{*}{ ESR1 Xbal polymorphism } & AA & $n(\%)$ & $92(34.59)$ \\
\hline & AG & $n(\%)$ & $129(48.50)$ \\
\hline & GG & $n(\%)$ & $45(16.92)$ \\
\hline
\end{tabular}

Table II. Cognitive functions vs. APOE polymorphism

\begin{tabular}{|c|c|c|c|c|c|c|c|c|c|c|c|c|}
\hline \multirow[t]{3}{*}{ Cognitive function } & \multirow{2}{*}{\multicolumn{2}{|c|}{ Total }} & \multicolumn{8}{|c|}{ APOE } & \multirow{2}{*}{\multicolumn{2}{|c|}{$\begin{array}{c}\text { Comparisons } \\
\text { between } A P O E \\
\text { genotypes }\end{array}$}} \\
\hline & & & \multicolumn{2}{|c|}{$\varepsilon 2 / \varepsilon 3$} & \multicolumn{2}{|c|}{$\varepsilon 3 / \varepsilon 3$} & \multicolumn{2}{|c|}{$\varepsilon 3 / \varepsilon 4$} & \multicolumn{2}{|c|}{$\varepsilon 4 / \varepsilon 4$} & & \\
\hline & Mean & SD & Mean & SD & Mean & SD & Mean & SD & Mean & SD & $F$ & $P$-value \\
\hline $\mathrm{NCl}$ & 83.2 & 17.4 & 92.7 & 14.7 & 83.2 & 14.4 & 76.4 & 22.6 & 68.8 & 21.4 & 12.653 & $<0.001$ \\
\hline Memory & 88.0 & 16.9 & 91.5 & 15.9 & 87.6 & 15.6 & 84.7 & 21.5 & 88.2 & 18.7 & 1.289 & 0.279 \\
\hline Verbal memory & 89.5 & 19.2 & 93.7 & 19.6 & 89.5 & 18.1 & 83.4 & 23.5 & 91.1 & 14.4 & 2.225 & 0.086 \\
\hline Visual memory & 91.9 & 15.5 & 93.3 & 11.6 & 91.4 & 15.7 & 92.9 & 16.6 & 90.2 & 21.4 & 0.333 & 0.802 \\
\hline Processing speed & 79.3 & 14.6 & 82.2 & 15.0 & 78.9 & 15.0 & 77.4 & 13.2 & 79.2 & 12.6 & 0.942 & 0.421 \\
\hline Executive functioning & 78.4 & 25.8 & 93.2 & 19.5 & 78.4 & 24.0 & 69.7 & 27.5 & 52.3 & 27.7 & 15.160 & $<0.001$ \\
\hline Psychomotor speed & 82.9 & 18.3 & 91.5 & 13.9 & 82.3 & 16.1 & 76.3 & 25.3 & 76.1 & 21.9 & 6.894 & $<0.001$ \\
\hline Reaction time & 87.5 & 16.3 & 93.8 & 20.0 & 85.4 & 14.2 & 87.5 & 15.2 & 87.1 & 19.8 & 3.663 & 0.013 \\
\hline Complex attention & 81.0 & 28.6 & 95.9 & 19.9 & 81.9 & 26.1 & 67.9 & 33.8 & 55.7 & 32.6 & 13.757 & $<0.001$ \\
\hline Cognitive flexibility & 77.1 & 27.0 & 92.4 & 20.9 & 77.3 & 24.9 & 66.0 & 30.5 & 53.1 & 27.6 & 14.133 & $<0.001$ \\
\hline
\end{tabular}

Processing speed was better in women who were TT homozygotes than in women with TC and CC genotypes. Executive functioning and cognitive flexibility were lower in women with TT genotype than in those with TC and CC genotypes.

Four cognitive functions - memory, verbal memory, visual memory and processing speed depended on ESR1 Xbal (Table IV). Women with $A A$ and $A G$ genotypes had better above-mentioned cognitive functions than those who were GG homozygotes.
Cognitive functions vs interaction between $A P O E$ and ESR 1 polymorphisms

Memory, visual memory, processing and psychomotor speeds depended significantly on the interaction between APOE and ESR1 Pvull polymorphisms (Table III and Figure 1). In women carrying the $\mathrm{C}$ allele of the Pvull polymorphism (TC and CC) cognitive functions were the best in the presence of the $\varepsilon 2 / \varepsilon 3$ genotype, lower if they possessed $\varepsilon 3 / \varepsilon 3$ and the lowest if they possessed 
Table III. Cognitive functions vs. ESR1 Pvull polymorphism and vs. interaction with APOE polymorphism

\begin{tabular}{|c|c|c|c|c|c|c|c|c|c|c|}
\hline \multirow[t]{3}{*}{ Cognitive function } & \multicolumn{6}{|c|}{ Pvull } & \multicolumn{4}{|c|}{ Comparisons of cognitive functions } \\
\hline & \multicolumn{2}{|c|}{ TT } & \multicolumn{2}{|c|}{ TC } & \multicolumn{2}{|c|}{ CC } & \multicolumn{2}{|c|}{ Vs. Pvull } & \multicolumn{2}{|c|}{ Vs. Pvull * APOE } \\
\hline & Mean & SD & Mean & SD & Mean & SD & $F$ & $P$-value & $F$ & $P$-value \\
\hline $\mathrm{NCl}$ & 81.2 & 18.2 & 84.0 & 17.1 & 83.8 & 17.2 & 0.657 & 0.519 & 0.740 & 0.565 \\
\hline Memory & 89.2 & 18.2 & 89.5 & 15.6 & 84.3 & 17.1 & 2.368 & 0.096 & 2.657 & 0.033 \\
\hline Verbal memory & 89.5 & 17.8 & 91.2 & 19.8 & 86.7 & 19.6 & 1.226 & 0.295 & 0.724 & 0.576 \\
\hline Visual memory & 93.6 & 18.9 & 92.7 & 14.4 & 88.9 & 12.8 & 1.946 & 0.145 & 2.886 & 0.023 \\
\hline Processing speed & 80.5 & 12.8 & 80.8 & 14.4 & 75.7 & 16.3 & 3.064 & 0.048 & 3.117 & 0.016 \\
\hline Executive functioning & 72.2 & 27.5 & 80.7 & 25.1 & 81.2 & 24.4 & 3.084 & 0.047 & 0.512 & 0.727 \\
\hline Psychomotor speed & 82.8 & 16.7 & 82.1 & 19.1 & 84.2 & 18.8 & 0.270 & 0.763 & 3.028 & 0.018 \\
\hline Reaction time & 88.6 & 15.4 & 85.4 & 15.7 & 89.8 & 17.7 & 1.881 & 0.155 & 1.753 & 0.139 \\
\hline Complex attention & 75.3 & 29.9 & 83.8 & 28.1 & 82.1 & 27.7 & 2.138 & 0.120 & 0.230 & 0.921 \\
\hline Cognitive flexibility & 71.1 & 28.4 & 79.4 & 26.8 & 79.5 & 25.4 & 2.995 & 0.050 & 0.448 & 0.774 \\
\hline
\end{tabular}

Table IV. Cognitive functions vs. ESR1 Xbal polymorphism and vs. interaction with APOE polymorphism

\begin{tabular}{|c|c|c|c|c|c|c|c|c|c|c|}
\hline \multirow[t]{3}{*}{ Cognitive function } & \multicolumn{6}{|c|}{ Xbal } & \multicolumn{4}{|c|}{ Comparisons of cognitive functions } \\
\hline & \multicolumn{2}{|c|}{ AA } & \multicolumn{2}{|c|}{ AG } & \multicolumn{2}{|c|}{ GG } & \multicolumn{2}{|c|}{ Vs. Xbal } & \multicolumn{2}{|c|}{ Vs. $X b a l^{*} A P O E$} \\
\hline & Mean & SD & Mean & SD & Mean & SD & $F$ & $P$-value & $F$ & $P$-value \\
\hline $\mathrm{NCl}$ & 84.7 & 16.7 & 83.4 & 18.0 & 79.3 & 17.0 & 1.501 & 0.225 & 2.494 & 0.050 \\
\hline Memory & 90.9 & 17.8 & 88.8 & 15.6 & 79.8 & 16.3 & 7.111 & 0.001 & 1.598 & 0.175 \\
\hline Verbal memory & 91.5 & 18.7 & 91.0 & 19.0 & 81.4 & 19.3 & 5.039 & 0.007 & 1.219 & 0.303 \\
\hline Visual memory & 94.2 & 17.9 & 91.9 & 13.9 & 87.3 & 13.6 & 3.043 & 0.049 & 2.519 & 0.042 \\
\hline Processing speed & 80.4 & 13.4 & 80.9 & 13.9 & 72.6 & 17.4 & 6.011 & 0.003 & 1.798 & 0.130 \\
\hline Executive functioning & 76.8 & 24.7 & 80.3 & 27.5 & 76.3 & 23.0 & 0.653 & 0.521 & 1.035 & 0.390 \\
\hline Psychomotor speed & 84.8 & 17.0 & 82.6 & 18.6 & 79.7 & 19.8 & 1.213 & 0.299 & 3.771 & 0.005 \\
\hline Reaction time & 89.3 & 13.7 & 86.7 & 16.9 & 86.2 & 19.1 & 0.841 & 0.433 & 2.058 & 0.087 \\
\hline Complex attention & 80.5 & 27.3 & 82.5 & 29.3 & 77.4 & 29.4 & 0.561 & 0.572 & 1.169 & 0.325 \\
\hline Cognitive flexibility & 75.9 & 25.7 & 78.8 & 28.9 & 74.7 & 24.4 & 0.545 & 0.581 & 1.258 & 0.287 \\
\hline
\end{tabular}

the $\varepsilon 4$ allele. Different relations were observed in women with TT genotype of the Pvull polymorphism - cognitive functions were not decreased in women with the $\varepsilon 4$ allele.

Similarly, interaction between APOE and ESR 1 $X b a l$ polymorphisms had a significant impact on $\mathrm{NCl}$, visual memory and psychomotor speed (Table IV and Figure 2). In women with AG and GG genotypes of the $\mathrm{Xbal}$ polymorphism cognitive functions were the best if women possessed $A P O E$ $\varepsilon 2 / \varepsilon 3$ genotype, lower in the presence of $\varepsilon 3 / \varepsilon 3$ genotype, and the lowest if they possessed the $\varepsilon 4$ allele. Different relations were observed in women having AA genotype of the Xbal polymorphism for which cognitive functions were not decreased in women with the $\varepsilon 4$ allele.
Cognitive functions vs interaction between Pvull and Xbal polymorphisms of ESR 1 gene

$\mathrm{NCl}$ and six cognitive functions differed between genotypes of Pvull and Xbal combined (Table V). Women who simultaneously carried CC Pvull and GG Xbal genotypes had the lowest cognitive functions mentioned above, women with TC and AA or CC and AG demonstrated the best, while women with TT and AA or TC and AG had moderate outcomes.

\section{Discussion}

Old age is a risk factor for cognitive decline. In the aging population, there is a high prevalence of mild cognitive impairment $(\mathrm{MCl})$, which increases 

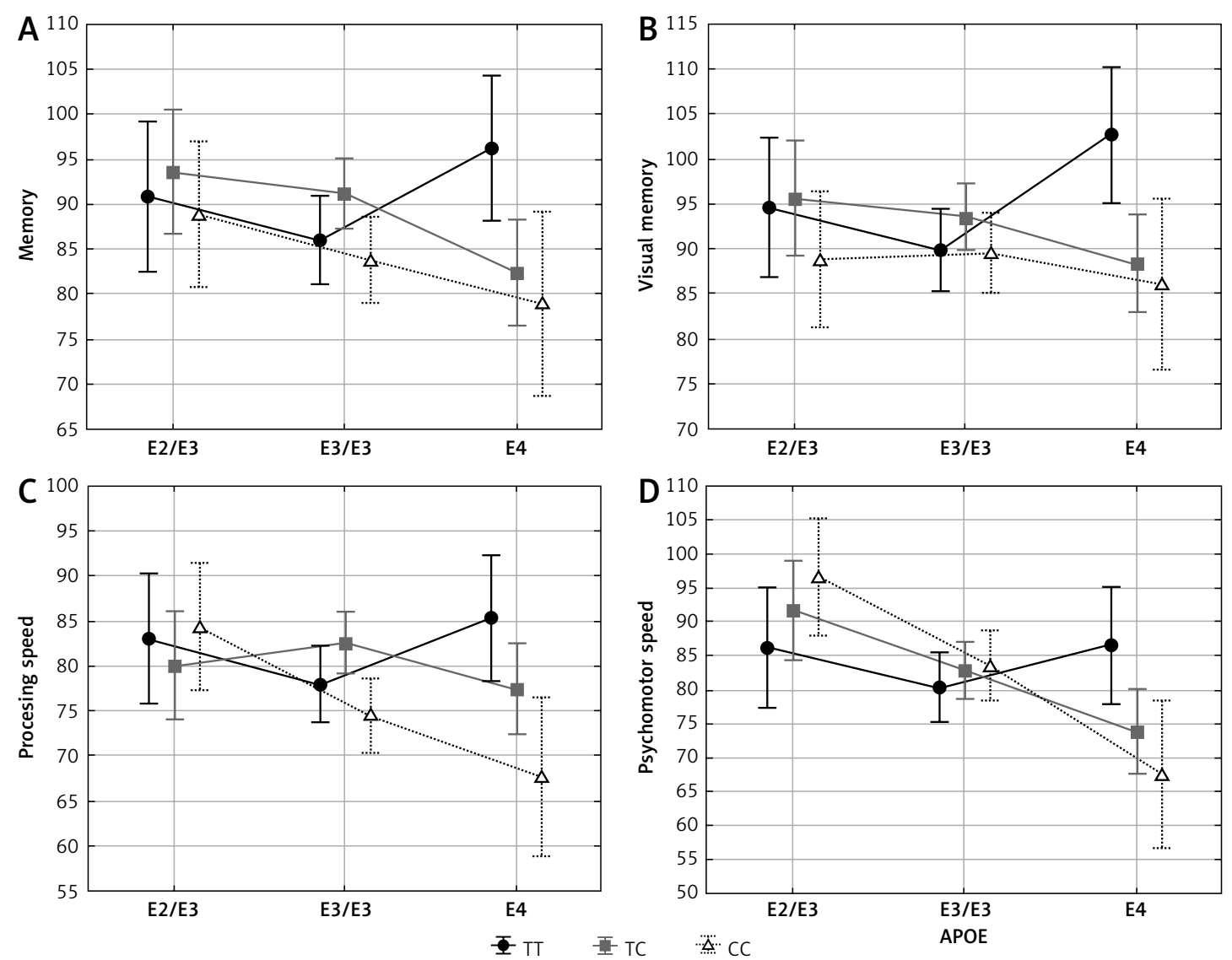

Figure 1. Significant effect of interaction between APOE and ESR1 Pvull polymorphisms on cognitive functions
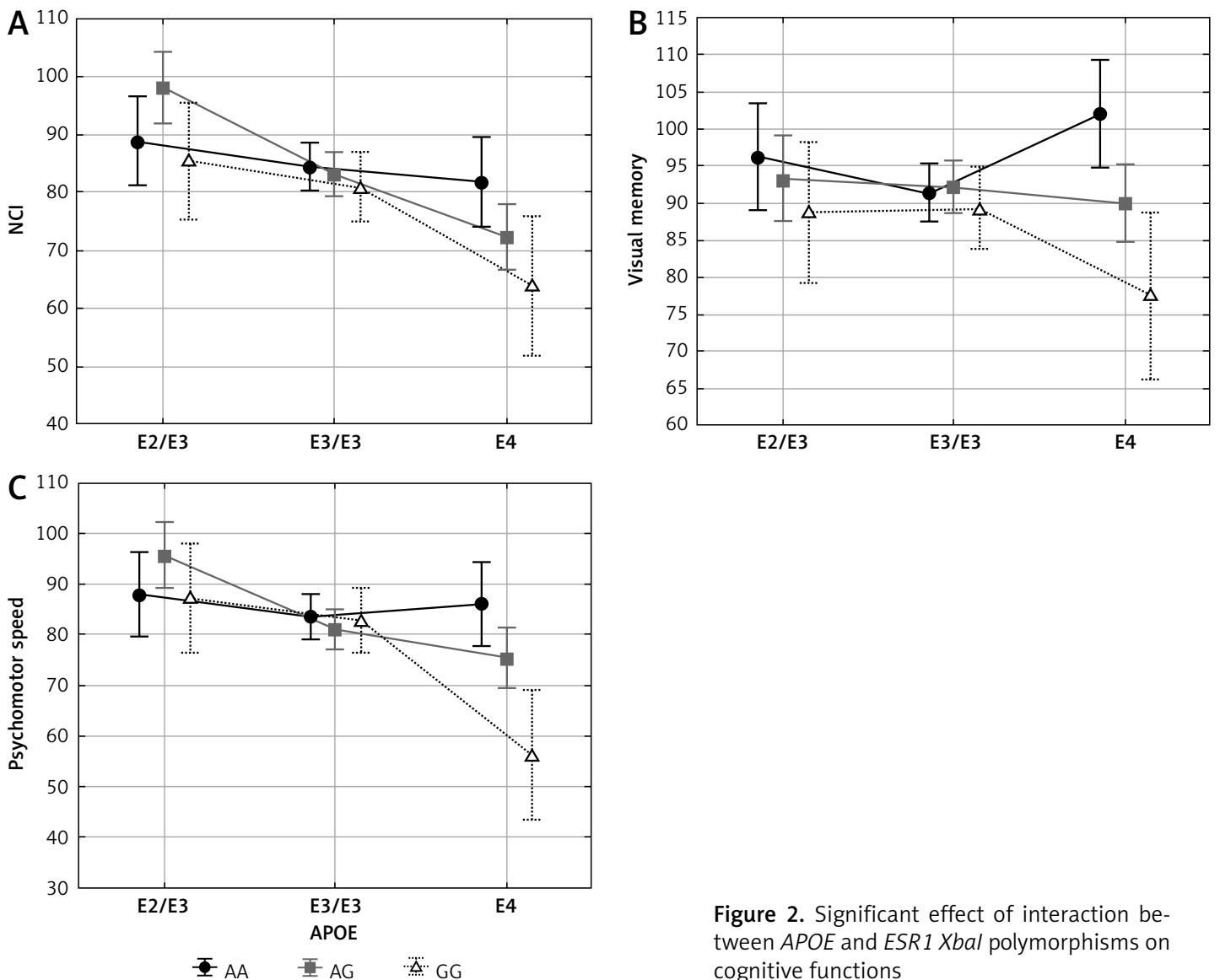

Figure 2. Significant effect of interaction between $A P O E$ and ESR 1 Xbal polymorphisms on cognitive functions 
Table V. Cognitive functions vs. interactions of Pvull and Xbal of ESR 1 polymorphism

\begin{tabular}{|c|c|c|c|c|c|c|c|c|c|c|c|c|}
\hline \multirow[t]{2}{*}{ Cognitive function } & \multicolumn{2}{|c|}{ TT and AA } & \multicolumn{2}{|c|}{$\mathrm{TC}$ and $\mathrm{AG}$} & \multicolumn{2}{|c|}{ CC and GG } & \multicolumn{2}{|c|}{ TC and $A A$} & \multicolumn{2}{|c|}{$\mathrm{CC}$ and $\mathrm{AG}$} & \multicolumn{2}{|c|}{$\begin{array}{l}\text { Comparisons } \\
\text { between groups }\end{array}$} \\
\hline & Mean & SD & Mean & SD & Mean & SD & Mean & SD & Mean & SD & $F$ & $P$-value \\
\hline $\mathrm{NCl}$ & 82.7 & 17.8 & 82.4 & 17.9 & 79.6 & 17.2 & 90.7 & 10.7 & 90.1 & 15.3 & 2.805 & 0.026 \\
\hline Memory & 89.2 & 18.6 & 87.9 & 15.6 & 80.1 & 16.6 & 95.9 & 14.4 & 90.6 & 16.2 & 3.995 & 0.004 \\
\hline Verbal memory & 89.5 & 18.3 & 89.7 & 19.8 & 81.6 & 19.6 & 97.6 & 19.2 & 94.4 & 17.2 & 3.403 & 0.010 \\
\hline Visual memory & 93.7 & 19.5 & 91.9 & 14.9 & 87.6 & 13.8 & 95.9 & 11.8 & 90.8 & 11.2 & 1.446 & 0.219 \\
\hline Processing speed & 80.2 & 12.7 & 80.7 & 14.3 & 72.9 & 17.8 & 81.0 & 15.4 & 79.9 & 13.0 & 2.500 & 0.043 \\
\hline $\begin{array}{l}\text { Executive } \\
\text { functioning }\end{array}$ & 74.4 & 26.5 & 79.8 & 26.7 & 76.5 & 23.4 & 84.3 & 16.6 & 88.2 & 24.5 & 1.940 & 0.104 \\
\hline Psychomotor speed & 82.7 & 17.3 & 80.0 & 19.4 & 79.6 & 20.2 & 91.2 & 14.7 & 91.0 & 14.2 & 3.640 & 0.007 \\
\hline Reaction time & 88.5 & 14.5 & 84.0 & 16.3 & 87.4 & 18.5 & 91.4 & 11.3 & 93.4 & 16.2 & 2.622 & 0.035 \\
\hline Complex attention & 77.2 & 29.3 & 82.3 & 29.9 & 77.5 & 29.8 & 90.3 & 17.6 & 88.9 & 23.2 & 1.692 & 0.152 \\
\hline Cognitive flexibility & 73.1 & 27.7 & 78.3 & 28.7 & 74.8 & 24.9 & 84.1 & 16.1 & 86.6 & 24.9 & 1.810 & 0.127 \\
\hline
\end{tabular}

Other combinations of Pvull and Xbal were not analyzed due to the very small sample sizes or even empty cells $(N=2$ for TT and GG, $N=$ 4 for $T T$ and $A G, N=O$ for $C C$ and $A A, N=O$ for $T C$ and $G G)$.

the risk of AD. It is forecast that by 2050 over 100 million people will develop such cognitive problems. $\mathrm{MCl}$ and dementia have consequences, especially for affected people but also for their caregivers, the health care delivery system and society in general. The problem especially applies to women after menopause when levels of estrogen, which have a neuroprotective effect, begin to drop significantly. In about $80 \%$ of women in the postmenopausal state neuronal degeneration may lead to difficulties in concentrating, overreacting or forgetfulness [21]. Menopause affects various activities of women's life [22]; among its effects, a decline in neurocognitive functions during the peri- and postmenopausal periods is observed [23].

The latest experimental data indicate some morphological changes in the hippocampus of postmenopausal female mice, i.e. mitochondrial damage, lipofuscin deposition and microtubule degradation [24]. In turn, in the study of Albert et al. [25], the effect of estrogen on the hippocampus and cognitive function was confirmed. The authors observed increased bilateral posterior hippocampal voxel-based gray-matter volume in women taking $2 \mathrm{mg}$ of estrogen, while in women who received a placebo or $1 \mathrm{mg}$ of estrogen no such effect was noted [25].

Age-related cognitive functions depend on various genetic risk factors, including $A P O E$ and ESR1. The first purpose of the present study was to analyze whether there are relations between both APOE and ESR 1 polymorphisms and several cognitive functions in a large group of postmenopausal women. We observed that women with $\varepsilon 4 /$ $\varepsilon 4$ show significantly lower executive functioning, psychomotor speed, reaction time, complex attention as well as cognitive flexibility compared to those with other APOE genotypes. The study of Schoemaker et al. [26] revealed significant positive correlations between familiarity performance and the volume of the perirhinal and entorhinal cortices as well as between recollection performance and hippocampal volume in carriers of APOE $\varepsilon 4$. Levels of ApoE were found to be higher in women and related to lifespan and cognitive function [27]. In turn, in elderly women who were carriers of the $A P O E$ \&4 allele and exposed to traffic pollution, cognitive impairment in the visuospatial domain was demonstrated [28]. Similarly, the presence of some depressive symptoms has a significant effect on cognitive impairment, which is increased in $A P O E \& 4$ carriers [29]. It was also demonstrated that in post-menopausal women the correlation between CRP level and cognitive functions may be modified by apolipoprotein E genotypes [30]. In addition, an enhanced negative effect of testosterone on cognition was found in postmenopausal women with at least one APOE \&4 allele [31].

In the case of ESR 1 polymorphisms we observed that memory, verbal memory, visual memory and processing speed were at the lowest level in $G$ allele homozygotes of the Xbal polymorphism. In contrast, women with CC genotype of the Pvull polymorphism had lower processing speed and cognitive flexibility but higher executive functioning. Data regarding the ESR 1 polymorphisms are often contradictory. Some studies show such a relationship while others do not. In the study of Elcoroaristizabal et al. [32] an association between the APOE $\varepsilon 4$ allele and amnesic mild cog- 
nitive impairment was found while no relation to cognition was observed for ESR1 polymorphisms in elderly women. In contrast, in the same study the polymorphisms within the ESR2 gene were associated with lower cognitive performance [30]. Similar findings were described by Ryan et al. [33]. No relationship between ESR1 polymorphisms and $A D$ or vascular dementia was found in older Jewish women [34]. On the other hand, the study of Ma et al. [9] analyzing the same relationship between twenty ESR 1 polymorphisms and cognition in a group of Chinese older adults demonstrated that eight polymorphisms may be considered as markers for episodic memory decline at an earlier stage. In the study of Yaffe et al. [35] cognitive impairments were more likely to occur in women than men. The rs9340799 (Xbal) polymorphism in the ESR 1 gene was associated with cognitive decline in univariate analysis and after adjustment for age, educational level and score of 3MS (Modified Mini-Mental State) the correlation was slightly stronger. Such a relationship was not observed in the case of men [33].

The main goal of our study was to analyze the impact of the interaction between APOE and ESR1 polymorphisms on cognitive functions in the analyzed women. In the case of interactions between ESR1 Pvull polymorphism and APOE, significant differences in the domains of memory, visual memory, processing and psychomotor speeds were observed. The lowest cognitive functions characterized women with Pvull TC and/or CC genotypes with simultaneous presence of at least one APOE $\varepsilon 4$ allele. The best cognition was observed for women with TC and/or CC and $\varepsilon 2 /$ $\varepsilon 3$ genotypes. Otherwise, women with Pvull TT seemed to be protected from cognitive decline even in the presence of the APOE $\varepsilon 4$ allele, and their functions did not get lower with the $A P O E$ genotypes. Similar findings in regard to the interactions between ESR $1 \mathrm{Xbal}$ and APOE polymorphisms were demonstrated. Women with $X b a$ I AG and/or GG genotypes and the APOE $\varepsilon 4$ allele had the lowest cognition compared to women with $X b a l$ AG and/or GG genotypes but having $\varepsilon 2$ or $\varepsilon 3$ alleles. In women with $X b a l$ AA and APOE $\varepsilon 4$, smaller deterioration in $\mathrm{NCl}$ as well as better visual memory and psychomotor speed was observed.

The study of Fernández-Martínez et al. [13] showed increased risk of mild dementia and $A D$ in the simultaneous presence of the APOE $\varepsilon 4$ allele and polymorphic variants of both $\mathrm{Xbal}$ and Pvull polymorphisms within the ESR1 gene. Opposite to our study, Fehsel et al. [11] found no relation of ESR 1 polymorphisms and cognition, but minor variants of ESR2 polymorphisms had a significant impact on executive function in women carrying the $A P O E \& 4$ allele. In addition, the authors observed that air pollution increased the risk of cognitive decline in women. In male patients with $A D, E S R 1 P P$ and $X X$ genotypes increased the risk of the disease and the risk was especially high in those with at least one APOE $\varepsilon 4$ allele $(O R=13.3)$ [36]. It was also demonstrated that wild-type genotypes (i.e. PP and XX) of ESR1 of Pvull and Xbal polymorphisms were associated with a faster cognitive decline in women with AD. Also, these genotypes decreased ApoE levels in male patients [36].

Cognitive functions in postmenopausal women may also correlate with biochemical, environmental or social factors. Previously, the impact of some of them, i.e. education, health behaviors, serum hormones and CRP protein concentrations, on cognitive functions was analyzed $[23,30,31$, 37]. The impact of cardiovascular risk factors on cognition was also considered [38, 39]. However, further studies are needed to understand the wide range of risk factors of cognition impairment as well as the interactions between them.

In conclusion, the AA and TT genotypes of estrogen receptor $\alpha$ polymorphisms protect postmenopausal women having the $\varepsilon 4$ allele of the $A P O E$ polymorphism from low cognitive functions. $\mathrm{NCl}$, memory, verbal memory, processing speed, psychomotor speed as well as reaction time were decreased the most in postmenopausal women who simultaneously carried the CC Pvull and GG $\mathrm{Xbal}$ genotypes.

\section{Conflict of interest}

The authors declare no conflict of interest.

\section{References}

1. Au A, Feher A, McPhee L, Jessa A, Oh S, Einstein G. Estrogens, inflammation and cognition. Front Neuroendocrinol 2016; 40: 87-100.

2. Królik M, Milnerowicz $\mathrm{H}$. The effect of using estrogens in the light of scientific research. Adv Clin Exp Med 2012; 21: 535-43.

3. McEwen B, Akama K, Alves S, et al. Tracking the estrogen receptor in neurons: implications for estrogen-induced synapse formation. Proc Natl Acad Sci USA 2001; 98: 7093-100.

4. Rocca WA, Grossardt BR, Shuster LT. Oophorectomy, estrogen, and dementia: a 2014 update. Mol Cell Endocrinol 2014; 389: 7-12.

5. LeBlanc ES, Janowsky J, Chan BK, Nelson HD. Hormone replacement therapy and cognition: systematic review and meta-analysis. JAMA 2001; 285: 1489-99.

6. Zhou A, Liu X, Xia T, Li F, Wang J, Li J. Estrogen receptor alpha gene (ESR1) polymorphism and its interaction with smoking and drinking contribute to susceptibility of systemic lupus erythematosus. Immunol Res 2017; 65: 951-6.

7. Hu X, Jiang L, Tang C, et al. Association of three single nucleotide polymorphisms of ESR1 with breast cancer susceptibility: a meta-analysis. J Biomed Res 2017; 31: 213-25. 
8. Lee YH, Song GG. Estrogen receptor 1 Pvull and Xbal polymorphisms and susceptibility to Alzheimer's disease: a meta-analysis. Genet Mol Res 2015; 14: 9361-9.

9. Ma SL, Tang NL, Leung GT, Fung AW, Lam LC. Estrogen receptor alpha polymorphisms and the risk of cognitive decline: a 2-year follow-up study. Am J Geriatr Psychiatry 2014; 22: 489-98.

10. Gujski M, Pinkas J, Wierzbińska-Stępniak A, Owoc A, Bojar I. Does genetic testing for ER alpha gene polymorphisms provide new possibilities of treatment for cognitive function disorders in postmenopausal women? Arch Med Sci 2017; 13: 1224-32.

11. Fehsel K, Schikowski T, Jänner $M$, et al. Estrogen receptor beta polymorphisms and cognitive performance in women: associations and modifications by genetic and environmental influences. J Neural Transm (Vienna) 2016; 123: 1369-79.

12. Larifla L, Armand C, Bangou J, et al. Association of APOE gene polymorphism with lipid profile and coronary artery disease in Afro-Caribbeans. PLoS One 2017; 12 e0181620.

13. Fernández-Martínez M, Elcoroaristizabal Martín X, Blan co Martín E, et al. Oestrogen receptor polymorphisms are an associated risk factor for mild cognitive impairment and Alzheimer disease in women APOE \{varepsilon\}4 carriers: a case-control study. BMJ Open 2013; 3: e003200.

14. Kowalska A. The genetics of dementias. Part 3: a molec ular basis for the multifactorial inheritance of sporadic Alzheimer's disease. Postepy Hig Med Dosw 2009; 63: 577-82.

15. Zak I, Balcerzyk A, Sarecka B, Niemiec P, Ciemniewski Z, Dylag S. Contemporaneous carrier-state of two or three "proatherosclerotic" variants of APOE, ICAM1, PPARA and PAI-1 genes differentiate CAD patients from healthy individuals. Clin Chim Acta 2005; 362: 110-8.

16. Nao J, Sun H, Wang Q, et al. Adverse effects of the apolipoprotein epsilon4 allele on episodic memory, task switching and gray matter volume in healthy young adults. Front Hum Neurosci 2017; 11: 346.

17. Nathan BP, Barsukova AG, Shen F, McAsey M, Struble RG. Estrogen facilitates neurite extension via apolipoprotein $E$ in cultured adult mouse cortical neurons. Endocrinology 2004; 145: 3065-73.

18. Skałba P. Signs of withdrawal. In: Clinical Endocrinology. Milewicz A (ed.). Polish Endocrine Society, Wroclaw 2012.

19. Gualiteri CT, Johnson LG. Reliability and validity of computerized neurocognitive test battery, CNS Vital Signs. Arch Clin Neuropsychol 2006: 21: 623-43.

20. Yang YG, Kim JY, Park SJ, Kim SW, Jeon OH, Kim DS. Apolipoprotein E genotyping by multiplex tetra-primer amplification refractory mutation system PCR in single reaction tube. J Biotechnol 2007; 131: 106-10.

21. Karamese M, Aksak S, Gundogdu OB, Unal B. A new hypothesis about hematopoietic $\mathrm{Pbx}$-interaction protein (HPIP): can it be a key factor in neurodegeneration in the post-menopausal period? Med Hypotheses 2013; 81: 470-6.

22. Raczkiewicz D, Owoc A, Lyubinets O, Wierzbińska-Stępniak A, Bojar I. Effect of menopause on activity of women in East European countries. Eur J Med Technol 2017; 1: $13-28$.

23. Gujski M, Raczkiewicz D, Rzemek C, et al. Health behaviours of peri- and post-menopausal women performing intellectual work vs. cognitive functions. Eur J Med Technol 2016; 3: 45-55.
24. Yan Y, Cheng L, Chen X, et al. Estrogen deficiency is associated with hippocampal morphological remodeling of early postmenopausal mice. Oncotarget 2017; 8: 21892-902.

25. Albert K, Hiscox J, Boyd B, Dumas J, Taylor W, Newhouse P. Estrogen enhances hippocampal gray-matter volume in young and older postmenopausal women: a prospective dose-response study. Neurobiol Aging 2017; 56: 1-6.

26. Schoemaker D, Poirier J, Collins DL, Gauthier S, Pruessner JC. Familiarity deficits in cognitively normal aging individuals with APOE epsilon4: a follow-up investigation of medial temporal lobe structural correlates. Alzheimers Dement 2017; 9: 21-4.

27. Muenchhoff J, Song F, Poljak A, et al. Plasma apolipoproteins and physical and cognitive health in very old individuals. Neurobiol Aging 2017; 55: 49-60.

28. Schikowski T, Vossoughi M, Vierkötter A, et al. Association of air pollution with cognitive functions and its modification by APOE gene variants in elderly women. Environ Res 2015; 142: 10-6.

29. Rajan KB, Wilson RS, Skarupski KA, Mendes de Leon CF, Evans DA. Gene-behavior interaction of depressive symptoms and the apolipoprotein $\mathrm{E}$ \{varepsilon\}4 allele on cognitive decline. Psychosom Med 2014; 76: 101-8.

30. Bojar I, Gujski M, Pinkas J, Raczkiewicz D, Owoc A, Humeniuk $\mathrm{E}$. Interaction between $\mathrm{C}$-reactive protein and cognitive functions according to APOE gene polymorphism in post-menopausal women. Arch Med Sci 2016; 12: $1247-55$.

31. Bojar I, Pinkas J, Gujski M, Owoc A, Raczkiewicz D, Gustaw Rothenberg K. Postmenopausal cognitive changes and androgen levels in the context of apolipoprotein $\mathrm{E}$ polymorphism. Arch Med Sci 2017; 13: 1148-59.

32. Elcoroaristizabal Martín X, Fernández Martínez $M$, Galdos Alcelay L, et al. Progression from amnesic mild cognitive impairment to Alzheimer's disease: ESR1 and ESR2 polymorphisms and APOE gene. Dement Geriatr Cogn Disord 2011; 32: 332-41.

33. Ryan J, Carrière I, Amieva $\mathrm{H}$, et al. Prospective analysis of the association between estrogen receptor gene variants and the risk of cognitive decline in elderly women. Eur Neuropsychopharmacol 2013; 23: 1763-8.

34. Dresner-Pollak R, Kinnar T, Friedlander Y, Sharon N, Rosenmann H, Pollak A. Estrogen receptor beta gene variant is associated with vascular dementia in elderly women. Genet Test Mol Biomarkers 2009; 13: 339-42.

35. Yaffe K, Lindquist K, Sen S, et al. Estrogen receptor genotype and risk of cognitive impairment in elders: findings from the Health ABC study. Neurobiol Aging 2009; 30: 607-14.

36. Corbo RM, Gambina G, Ruggeri M, Scacchi R. Association of estrogen receptor alpha (ESR1) Pvull and Xbal polymorphisms with sporadic Alzheimer's disease and their effect on apolipoprotein E concentrations. Dement Geriatr Cogn Disord 2006; 22: 67-72.

37. Raczkiewicz D, Sarecka-Hujar B, Owoc A, Bojar I. Cognitive functions and serum cortisol concentration in perimenopausal and postmenopausal women working non-manually. Neuro Endocrinol Lett 2017; 38: 269-74.

38. Bojar I, Owoc J, Wojcik-Fatla A, Raszewski G, Stančiak J, Raczkiewicz D. Cognitive functions, lipid profile, and apolipoprotein E gene polymorphism in postmenopausal women. Ann Agric Environ Med 2015; 22: 313-9.

39. Ying $H$, Jianping $C$, Jianqing $Y$, Shanquan Z. Cognitive variations among vascular dementia subtypes caused by small-, large-, or mixed-vessel disease. Arch Med Sci 2016; 12: 747-53. 